\title{
The Construction of High Efficiency Human Bone Marrow Tissue Ex Vivo
}

\author{
Stephen G. Emerson, Bernhard O. Palsson, and Michael F. Clarke \\ Departments of Internal Medicine (S.G.E., M.F.C.), Pediatrics (S.G.E.), and Chemical Engineering (B.O.P.), \\ University of Michigan, Ann Arbor, Michigan 48109
}

\begin{abstract}
The successful ex vivo reconstruction of human bone marrow is an extraordinarily important basic scientific and clinical goal. Fundamentally, the system is the paradigm of a complex interactive tissue, in which the proliferation and regulated differentiation of one parenchymal cell type (the hematopoietic stem cell) is governed by the surrounding stromal cells. Understanding and reproducing the molecular interactions between bone marrow stromal cells and stem cells in tissue culture models is therefore the critical step in successful bone marrow tissue culture. Clinically, successful reconstruction of human bone marrow would permit the controlled production of mature blood cells for transfusion therapy, and immature bone marrow stem cells for bone marrow transplantation. In approaching the bone marrow culture system, we recognize the critical role that hematopoietic growth factors (HGFs) play in hematopoiesis. Since stromal cells in traditional human bone marrow cultures produce little HGFs, we have begun by asking whether local supplementation of hematopoietic growth factors via genetically engineered stromal cells might augment hematopoiesis in liquid cultures. The results indicate that locally produced GM-CSF and IL-3 do augment hematopoiesis for several weeks in culture. In combination with geometric and dynamic approaches to reconstructing physiological bone marrow microenvironments, we believe that this approach has promise for reconstructing human bone marrow ex vivo, thereby permitting its application to a variety of basic and clinical problems.
\end{abstract}

Key words: hematopoiesis, stem cell, perfusion, hematopoietic growth factor, genetic engineering

If one could successfully recreate the physiology of human bone marrow ex vivo, one could achieve several aims: 1) the detailed analysis of normal and leukemic hematopoiesis; 2) the manipulation of human bone marrow stem cells, including stem cell expansion for bone marrow transplantation, tumor cell purging of contaminated bone marrow prior to autologous transplantation, and (e.g., retroviral mediated) gene transfer into stem cells; and 3) the controlled production of mature blood cells for transfusion therapy.

These and other potential applications of longterm bone marrow culture have been evident since the original experiments of Dexter and Lajtha [1], which demonstrated that murine liquid bone marrow cultures could continue to produce progenitor cells and mature myeloid cells for over one year. However, attempts to extend these principles to human liquid marrow

Received October 12, 1990; accepted November 16, 1990. Address reprint requests to Stephen G. Emerson, University of Michigan Medical Center, Room 5510B MSRB1, 1150 West Medical Center Drive, Ann Arbor, MI 48109-0680. culture, and to improve the efficiency of such cultures, have been notably unsuccessful. $\mathrm{Hu}-$ man liquid bone marrow cultures produce continually decreasing numbers of mature blood cells and progenitors, and generally dissipate completely by $8-10$ weeks [2,3]. Moreover, cell production appears to be quite skewed towards myeloid cell production, particularly monocytes, and erythroid hematopoiesis is notably absent, even when erythropoietin is added. In fact, there is little reason to think that human liquid bone marrow cultures, as they are currently performed, promote stem cell survival and expansion to any significant extent. Thus the inefficiency of current human liquid bone marrow culture techniques has prevented its exploitation for the analysis and manipulation of human stem cells in vitro, and failed to permit the generation of mature blood cells in sufficient numbers to consider scale-up for clinical transfusion therapy.

We believe that recent advances in our understanding of hematopoietic cell and molecular biology, as well as in the cellular bioengineering of complex cultures, now permit us to rationally 
approach developing a truly efficient ex vivo model of human bone marrow. We have identified five distinct, but potentially interrelated areas in which current liquid marrow cultures fail to reproduce in vivo bone marrow design: 1) failure of quiescent cultured stromal cells to secrete hematopoietic growth factors; 2) lack of a normal, compact 3-dimensional geometry with stromal cells and extracellular matrix proteins at high density; 3) accumulation of toxic metabolites in traditional batch marrow cultures, which may poison stromal cells, hematopoietic cells, or both; 4) degradation of the cultured stromal and early hematopoietic cells by the toxic granular contents of mature granulocytes and macrophages that accumulate in liquid cultures; and 5) depletion of stem cells resulting from frequent sampling of non-adherent cells by the investigator. We hypothesize that the precise analysis and solution of these problems will lead to greatly improved human bone marrow cultures, which will permit improved analysis and manipulation of human bone marrow cultures for bone marrow transplantation and mature blood cell transfusion.

\section{STROMAL CELL PRODUCTION OF HEMATOPOIETIC GROWTH FACTORS}

The hematopoietic microenvironment, or stroma, has long been known to be a major architectural feature of bone marrow, including a complex meshwork of cells and extracellular matrix. Although the precise roles of these cells and matrix components was not early realized [4], it was immediately clear that without such a stroma hematopoiesis would rapidly die out. If no attempt was made to remove these stromal elements, hematopoiesis was maintained for periods of weeks to months [5]. This requirement for stromal accessory cells has been documented by many laboratories [6-8], and recently we and others have isolated homogeneous fibroblastoid cell strains that appear to perform as well as more complex stromal cell mixtures $[9,10]$.

The stromal cells and matrix proteins appear to provide two sorts of requisites for hematopoiesis: 1) secreted hematopoietic growth factors, or colony stimulating factors ( $\mathrm{CSFs}$ ) and 2) an adhesive microenvironment that maintains both high local growth factor concentrations and cellcell contact. To date, stromal fibroblasts and endothelial cells have been shown to be capable of producing granulocyte-macrophage colony stimulating factor (GM-CSF), granulocyte col- ony stimulating factor ( $\mathrm{G}$-CSF), interleukin 6 (IL-6), and probably macrophage colony stimulating factor (M-CSF) [11-17]. These polypeptides clearly support progenitor cell proliferation and differentiation, and may contribute to stem cell survival and proliferation as well. Several other hematopoietic growth factors have been described which are products of T lymphocytes or monocytes, including interleukins 1,3 , 4 and 5 [18-21]. Of these, IL-3 and GM-CSF are particularly interesting, because murine stem division sufficient to permit incorporation of transfected genetic material was promoted by WEHI-3 supernatants containing IL-3 and GMCSF [22].

The true in vivo stimuli for the production of these HGFs is not known. In vitro, however, endothelial cells and fibroblasts from a variety of tissues can transcribe and secrete GM-CSF, G-CSF, and IL-6 in response to signals provided by activated macrophages, such as IL-1 and tumor necrosis factor [11-17]. T cells and activated monocytes are therefore required for the in vitro production of all of these CSFs. This requirement may explain, in large part, why human liquid bone marrow cultures "run down" after a few weeks. Without exogenous stimuli, human $\mathrm{T}$ cells die in liquid culture, while monocytes remain quiescent. Thus, once the $T$ cells die out and monocytes are no longer activated, the fibroblasts and endothelial cells may no longer secrete CSFs and the bone marrow stem cells die. A continuous source of the proper CSFs, on the other hand, might circumvent this problem.

\section{TOXIC PRODUCTS FROM MATURE CELLS AND METABOLIC WASTE PRODUCTS - THE ROLE OF MEDIUM EXCHANGE}

A critical observation from the liquid culture experience is that secreted products of mature granulocytes and macrophages are toxic to the immature developing marrow cells. Initially, we observed that removal of maturing myeloid cells permitted the otherwise unobserved growth of erythroid and megakaryocytic cells in vitro [9]. We also found that such cultures generated more cells and grew longer than traditional whole marrow cultures. Re-adding mature myeloid cells to the original marrow innoculum returned the system to a low efficiency state. More recently, macrophages arising in liquid cultures have been shown to directly damage cultured stroma and immature hematopoietic cells [23]. These re- 
sults suggest that the slow but continuous perfusion of culture medium, removing mature cells as they lose their stromal adhesion receptors, would protect the culture microenvironment from the toxic granular and other secreted products of the mature myeloid cells.

Attempts to duplicate in vivo bone marrow perfusion conditions can now be built on the growing theoretical and practical experimental advances achieved with perfusion culture technologies from other systems. These advances have been made, in part, by the recognition of the differences between static in vivo culture systems and the dynamic in vivo situation. Perhaps the most important is the delivery of oxygen and nutrients, and the removal of inhibitory end products, such as lactate and ammonium ions [24]. For example glutamine has received particular attention as a major energy source for culture cells. As a consequence glutamine concentrations are often rapidly reduced to critically low values in static culture medium. Conversely, lowering peak concentrations of glutamine and glucose through continuous perfusion with lower glutamine and glucose concentrations can reduce the build-up of inhibitory end products, such as lactic acid and ammonium [25].

Local oxygen concentrations are another critical variable that is poorly modeled by static in vivo cultures. The solubility of oxygen in aqueous medium is low and concentrations surrounding a cell line growing on a flat surface only 1 $\mathrm{mm}$ beneath the surface of the medium have been estimated to be only $60 \%$ of that at the surface. The balance between the rate of oxygen consumption and rate of supply by diffusion that exists in vivo is thus disrupted. Several methods of enhancing $\mathrm{O}_{2}$ delivery in bioreactors have been developed, including gentle rocking with intermittent exposure to air [26], stirred tank reactors [27,28], surface aeration [29], microcarrier cultures [30] and airlift fermenters [31-35]. As discussed below, our perfusion chambers compare very favorably with these methods without introducing excessive shear stresses. Overall, we believe that the careful application of continuous perfusion technology to hematopoietic cultures can solve the problems of mature cell toxic secreted products, metabolite delivery and removal, and oxygenation which are inherent and severe in tradition T-flask Dexter cultures.

\section{IS STEM CELL SURVIVAL A SOLVABLE PROBLEM?}

Since the central goal of this project is the long-term maintenance of human bone marrow stem cells in vivo, it is critical to ask: Can this be done? What makes one think that this is a reasonable hope? Several lines of argument are, to us, convincing:

1. Long-term static liquid culture systems in the mouse have been maintained for 1 year or more $[1,32,33]$. Since the physiologies of murine and human hematopoiesis appear to be analagous (homologous hematopoietic growth factors, produced by similar stromal and circulating cells), this suggests that the failure to construct at least stable, low efficiency long-term human stem cell cultures is a technical and quantitative, not qualitative, failure.

2. Studies on human patients with chronic myelogenous leukemia indicate that stem cells placed into liquid culture probably do not die immediately. Instead, normal stem cells, whose progenitor progeny are not evident in the initial culture, persist and divide over the next two months, giving rise to clonable progenitor cells [34]. Since the transit time from stem cell to progenitor is unlikely to be long, this suggests that the initially plated stem cells are capable of surviving for a month or more, even in traditional, inefficient cultures.

3. Recent experiments using retroviral transfection to randomly incorporate marker genes followed by bone marrow transplantation indicate that an entire hematopoietic system may be repopulated from less than 5 stem cells, perhaps a single cell [22]. Thus, if advances made in culture practices succeeded in keeping only a fraction of the total stem cell pool alive, one should still be able to engineer a stable, efficient bone marrow ex vivo.

4. Stem cells survive and proliferate in vivo. Bone marrow transplants are routinely performed using donors $>40$ years old, with no evidence for a higher engrafting dose required than for childhood donors. There is no evidence that even a significant fraction of the stem cell pool is lost over decades in vivo. Therefore, in principle, stem cells should be supportable if the in vivo environment can be accurately mimicked. 


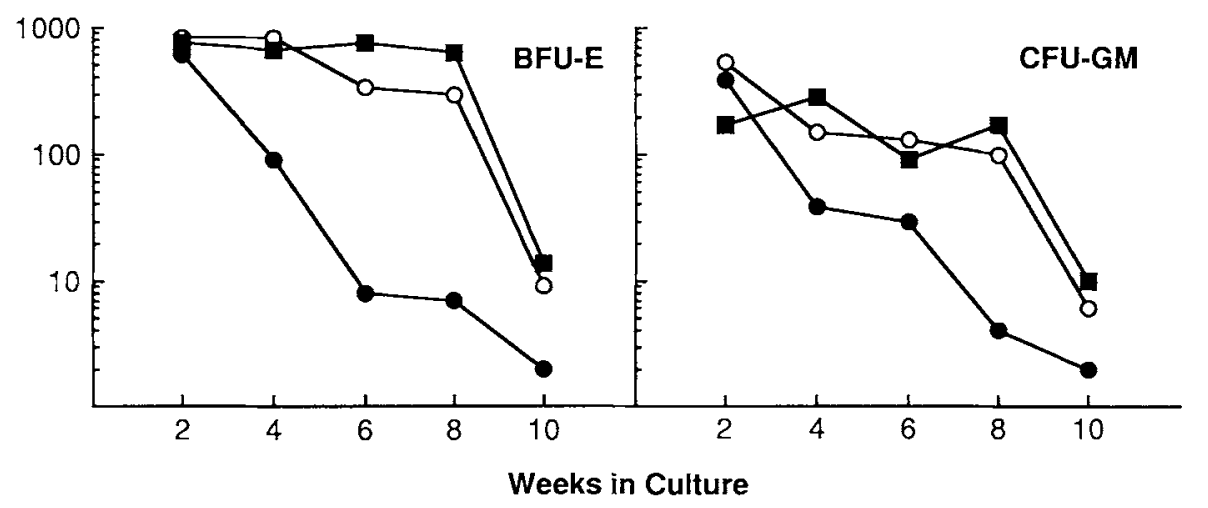

Fig. 1. Nonadherent progenitor cells arising in liquid culture from $10^{7}$ bone marrow mononuclear cells plated over normal marrow adherent layers (closed circles), GM-CSF transfected $\mathrm{NIH}-3 \mathrm{~T} 3$ cells (open circles), and GM-CSF/LL-3 transfected NIH-3T3 cells (closed squares). Untransfected NIH-3T3 cells failed to support any progenitor cell production for longer than 2 weeks.

Overall, these are persuasive arguments that it should be possible to keep human stem cells alive in vivo, under the proper circumstances. With the recent advances in hematopoietic cell biology, molecular genetics, and cellular bioengineering, we believe that now is the time to productively tackle and solve this problem.

\section{GROWTH FACTOR SUPPLEMENTATION WITH TRANSFECTED STROMAL CELLS}

We have therefore begun to address each of these problems with traditional human liquid bone marrow cultures, with the goal of developing and building a high efficiency ex vivo bone marrow. Our fundamental approach has been to begin by understanding the ways in which traditional cultures differ from hematopoiesis in vivo, and to adapt our culture systems to either better reflect the in vivo physiology or to bypass those physiologic requirements observed in vivo. As one example of this approach, we have used recombinant DNA technology to bypass the requirement for inflammatory induction of CSF production by bone marrow stromal cells. While bone marrow stromal cells in vivo undoubtedly secrete CSFs in the basal state, once explanted they fail to secrete CSFs unless stimulated with IL- $1 \alpha$ or TNF $\alpha$. To circumvent this limitation, while providing for the local secretion and presentation of CSFs as normally occurs in the bone marrow, we have therefore created NIH3T3 fibroblast cell lines transfected with plasmid constructs containing both a full length GM-CSF and IL-3 cDNAs driven by the metallothionine promoter and SV40 enhancer, which secrete these CSFs at $0.2-0.5 \mathrm{ng} / 10^{6}$ cells/day [35]. Utilizing these transfected fibroblast cell lines, we have established liquid marrow cultures under both traditional Dexter medium exchange schedules and more rapid, physiologic exchange schedules. Traditional Dexter cultures utilizing these stromal cells are quite interesting, supporting erythroid and myeloid progenitor cell proliferation to a substantially greater extent than simple bone marrow adherent cell monolayers (Figure 1). Moreover, when incorporated into a continuous perfusion bioreactor, these transfected stromal cells support continuous hematopoiesis, with continuous generation of HLA-DR ${ }^{+}$progenitor cells, for at least 100 days.

Based upon these results, experiments are now under way evaluating the effect of other candidate hematopoietic growth factors, including IL-6, IL-1 $\alpha$ and G-CSF. In addition, we are exploring the potential utility of alternative source of stromal cells for direct hematopoietic cultures. For example, based upon classic transplantation experiments, splenic fibroblasts might be a superior source of stromal cells to support erythropoiesis. We are therefore creating and testing the effects of distinct stromal cell types transfected with a variety of functional cDNAs. In addition, we are incorporating information from metabolic and molecular studies on isolated stromal cells into the design of specifically tailored hematopoietic bioreactors.

\section{PROSPECTS FOR HEMATOPOIETIC CULTURE BIOREACTORS}

Successful construction of hematopoietic bioreactors will have a tremendous impact on hematopoietic cell biology and on clinical practice. First, it will permit the detailed study of 
normal versus leukemic hematopoiesis in an in vitro system that accurately mimics the in vivo physiology. Second, it will permit the ex vivo manipulation of hematopoietic stem cells. This has major applications, including stem cell expansion for allogeneic transplantation, stem cell purging for the selective removal of tumor cells prior to autologous reinfusion, and transduction of hematopoietic stem cells for gene therapy. Finally, such bioreactors would permit the production of mature blood cells, under controlled conditions, for transfusion therapy. With over 30 million units of erythrocytes and over 10 million units of platelets transfused annually, this represents a tremendous demand on the health care system, and a extraordinary opportunity for bioengineering to circumvent the infectious hazards of volunteer donors.

In summary, successful ex vivo reconstruction of functioning human bone marrow would be a fundamental achievement in bioengineering and clinical research. The bone marrow is the source of pluripotent hematopoietic stem cells, the cells that give rise to all of the blood elements. Clinically, successful reconstruction of human bone marrow would permit the controlled production of mature blood cells for transfusion therapy, and immature bone marrow stem cells for bone marrow transplantation. With the recent advances in hematopoietic cell biology, molecular genetics, and cellular bioengineering, future research efforts should make significant strides towards to productively tackle and solve these problems.

\section{ACKNOWLEDGMENTS}

This research was supported by Award 8815658 from the Emerging Technologies Institution Progress of the National Science Foundation. We would like to thank Drs. Max Wicha and Gargi Upadhyaya for their contributions to these studies, and Ms. Trudy Ingland for her expert secretarial assistance.

\section{REFERENCES}

1. Dexter $\mathrm{TM}$, Lajtha LG: $\mathrm{Br} \mathrm{J}$ Haematol 28:525-530, 1974.

2. Gartner S, Kaplan H: Proc Natl Acad Sci USA 77:4756$4759,1980$.

3. Coulombel L, Eaves AC, Eaves CJ: Blood 62:291-297, 1983.

4. Bentley SA: Br J Haematol 50:1-6, 1982.

5. Dexter TM, Allen TD, Lajtha LG: J Cell Physiol 91:335344,1977 .
6. Chamberlain W, Barone J, Kedo A, Fried W: Blood 44:385-392, 1974.

7. Moore MA, Sheridan AP, Allen TD, Dexter TM: Blood 54:775-793, 1979.

8. Bentley SA, Knutsen T, Whang-Peng J: Exp Hematol 10:367-372, 1982.

9. Tsai S, Emerson SG, Sieff SA, Nathan DG: J Cell Physiol 127:137-145, 1986.

10. Song ZX, Thomas C, Innes D, Quesenberry PG: Exp Hematol 12:523-533, 1984

11. Broudy VC, Kaushansky K, Harlan JM, Adamson JW: J Immunol 139:464-468, 1986.

12. Sieff CA, Tsai S, Faller DV: J Clin Invest 79:48-51, 1987.

13. Fibbe WE, Van Damme J, Billiau A, Goselink HM, Voogt PJ, Van Eeden G, Ralph P, Altrock BW, Falkenburg JHF: Blood 71:430-435, 1988.

14. Lovhaug D, Pelus LM, Nordlie EM, Boyum A, Moor MAS: Exp Hematol 14:1037-1042, 1986.

15. Rennick D, Yang G, Gemmell L, Lee F: Blood 69:682 $691,1987$.

16. Ikebuchi $\mathrm{K}$, Wong GG, Clark SC, Ihle JN, Hirai $\mathrm{Y}$, Ogawa M: Proc Natl Acad Sci USA 84:9035-9039, 1987.

17. Broudy VC, Kaushansky K, Segal GM, Harlan JM, Adamson JW: Proc Natl Acad Sci USA 83:7467-7471, 1986.

18. Stanley ER, Bartocci A, Patinkin D, Rosendaal M, Bradley TR: Cell 45:667-674, 1986.

19. Yang YC, Ciarletta AB, Temple AP, Chung MP, Kovacic S, Witek-Gianotti JS, Leary AC, Kriz R, Donahue RE, Wong GG, Clark SC: Cell 47:3-10, 1986.

20. Sharma S, Mehta S, Morgan J, Maizel A: Science 235: 1498-1492, 1987.

21. Kinashi T, Harada N, Severinson $E$, Tanabe $T$, Sideras P, Konishi M, Azuma C, Tominaga A, BergstedtLindqvist S, Takahashi M, Matsuda F, Yaoita Y, Takatsu K, Honjo T: Nature 324:70-73, 1986.

22. Lemischka I, Mulligan RC: Cell 45:917-927, 1986.

23. Meagher RC, Salvado AJ, Wright DJ: Blood 72:273281,1988

24. Thomas JN: In Thill WG (ed): "Mammalian Cell Technology." 1986, pp 199-221.

25. Glacken MW, Felischaker RJ, Sinskey AJ: Biotech Bioeng 28:1376-1389, 1986.

26. Cole LA, Scheid JM, Tannen RL: Am J Physiol 251: C293-298, 1986.

27. Feder J, Tolbert WR: Sci Amer 248:36-43, 1983.

28. Feder J, Tolbert WR (eds): "Large Scale Mammalian Cell Culture." Academic Press, 1985.

29. Hu WS, Meiyer J, Wang DIC: Biotech Bioeng 17:209 215,1985

30. Aharonowitz Y, Cohen G: Sci Amer 245:140-152, 1981.

31. Birch JR, Thompson PW, Lambert K, Borastan R: In Feder J, Tolbert WR (eds): "Large-Scale Mammahian Cell Culture." Academic Press, 1985, pp 1-18.

32. Greenberger JS: Nature 275:752-754, 1978.

33. Mauch P, Greenberger JS, Botnick L, Hannan E, Hellman S: Proc Natl Acad Sci USA 77:2927-2930, 1980.

34. Coulombel L, Eaves C, Kalowsek D, Gupta C, Eaves A: J Clin Invest 75:961-969, 1986.

35. Caldwell J, Locey B, Clarke MF, Emerson SG, Palsson BO: Biotech Prog (in press 1991) 